УдК 342.84

\title{
СТАГНАЦИЯ ИЗБИРАТЕЛЬНЫХ СИСТЕМ
}

\author{
Александр Николаевич Чудинов, \\ chudinov_al@mail.ru \\ Омский государственный технический университет, \\ Россия, 644050, г. Омск, пр. Мира, 11
}

\begin{abstract}
Александр Николаевич Чудинов, кандидат технических наук, доцент кафедры электрической техники Омского государственного технического университета.

Обосновывается необходимость создания эффективной избирательной системы как регулирующего механизма государственного управления. Приведены признаки неэффективности всеобщих равных прямых выборов с минимальным количеством цензов пассивного и активного избирательного права. Показано отсутствие развития избирательных систем; представлены аргументы необходимости их развития с позиции теории автоматического управления. Предложены направления возможного совершенствования избирательных систем.
\end{abstract}

Ключевые слова: Избирательная система, эффективное управление, неравное избирательное право, избирательный ценз.

Человечество одновременно развивается в разных направлениях. И чем более сбалансировано развитие, тем меньше вероятность регресса. На данный момент «узким местом» развития общества являются система управления и определение вектора развития (четкая формулировка целей и задач развития). В мире и в России расцветает кризис системы управления. Экономический кризис является лишь следствием - симптомом болезни. И то, что экономический кризис многие ставят во главу угла, является грубой ошибкой. С симптомами (экономическим кризисом), конечно, необходимо бороться, и в данном направлении известен ряд эффективных методов и предлагаются новые (в том числе, и в России). При этом на задний план отодвигается сама болезнь кризис системы управления.

В настоящее время наиболее эффективной и социально справедливой формой правления считается демократическая представительная. Основным достоинством данной системы считается контроль над политической элитой (в том числе, «сменяемость власти»). Основные недостатки - неэффективность выбора политической элиты и отсутствие контроля над ней. В статье обоснован выбор этих недостатков как наиболее важных, показано отсутствие развития избирательных систем, которое позволило бы уменьшить или устранить вовсе данные недостатки, и предложены направления возможного решения данной проблемы с позиции меритократии.

Почему же выбор политической элиты демократическим путем на сегодняшний день является неэффективным? В первую очередь это связано с реализацией права делегировать свою власть политической элите. Делегирование власти осуществляется посредством выборов, процедура которых отражается в применяемой избирательной системе. Таким образом эффективность выбора политической элиты зависит от действующей избирательной системы.

На данный момент в мире наиболее распространены избирательные системы, которые по классификации можно отнести к всеобщим, равным, прямым, с тайным голо- 
сованием, альтернативным, с минимальным наличием цензов [1-9]. К цензам активного избирательного права обычно относятся оседлость (проживание в стране, регионе на протяжении нескольких месяцев или лет до момента проведения выборов), наличие гражданства, возраст (стандарт - 18 лет). Также не участвуют в выборах душевнобольные, недееспособные и преступники. К цензам пассивного избирательного права обычно добавляются следующие: наличие базового образования (в развитых странах на высокие посты - наличие высшего образования), повышенный возрастной ценз и служебный (по признаку занимаемой должности, профессиональной деятельности или духовного сана).

При всеобщих равных прямых выборах с минимальным количеством цензов пассивного и активного избирательного права власть избирается мнением большинства и эффективность этого выбора находится в прямой зависимости от медианного уровня интеллекта и образования граждан. В связи с особенностями человеческой природы, воспитанием и образованием способность совершить эффективный выбор исходя из известных фактов, а также понимание важности принимаемого решения и принятие ответственности за него присутствует только у небольшой части граждан. Отсутствие данных способностей у большинства избирателей приводит к тому, что выбор политических элит происходит или случайным образом, или навязывается правящим меньшинством (финансовые, военные, политические элиты), что значительно снижает эффективность систем управления, построенных на базе таких избирательных систем.

Признаками неэффективности всеобщих равных прямых выборов с минимальным количеством цензов пассивного и активного избирательного права можно считать:

1. Практически полное отсутствие прямых выборов министров и премьерминистров во всех странах мира, т. к. непрофессионал на данных должностях приведет к катастрофическим последствиям.

2. В части наиболее развитых стран используется система непрямых выборов (США, КНР, Германия), неравных (КНР).

3. Осуществляется дополнительная фильтрация кандидатов за счет партийных систем (дополнительные цензы пассивного избирательного права), из которых и выдвигается большинство кандидатов (США, КНР и многие другие страны).

4. Применяются технологии влияния на мнение большинства посредством средств массовой информации [10] (СМИ используются для смещения мнения большинства в нужную правящей элите сторону).

5. Экспертные мнения известных политиков, философов (Т. Джефферсон, И.А. Ильин, Н.А. Бердяев).

Систему управления государством можно рассматривать с позиции теории автоматического управления (ТАУ). Возникают трудности, связанные с многочисленными факторами, влияющими на поведение системы, многие из которых стохастические или трудно вычислимые и не позволяют анализировать все многообразие свойств данной системы. Но простейший общий анализ системы на основе сопоставления системы управления государством с технической системой вполне возможен.

С точки зрения ТАУ избирательная система является обратной связью в системе управления. В современном государстве, как и в любой сложной технической системе, в которой известны не все передаточные функции элементов системы, обеспечить устойчивость системы и регулирование выходных величин можно только с использованием обратной связи, а наиболее четкая (по сравнению с другими формами) обратная связь от граждан к правящей элите присутствует при демократической форме правления. При этом как и в технической системе при неправильно настроенном измеритель- 
ном элементе и/или неправильно настроенном (выбранном) регуляторе выходные параметры системы будут отличаться от желаемых, так и в государстве с «передовой» демократической формой правления результат не будет соответствовать желаемому при неверно «настроенной» избирательной системе. Таким образом, эффективная избирательная система является необходимым условием эффективности демократической формы правления.

Чем больше выходных величин объекта управления и сложнее система, тем больше обратных связей и сложнее законы управления. Накопление знаний, появление новых возможностей и взаимодействий между гражданами, новых акторов должны приводить к усложнению системы управления, к необходимости появления дополнительных обратных связей, к более сложным «регуляторам» (к более квалифицированным управляющим элитам, новым институтам управления). В большинстве же стран с демократической формой правления избирательная система не претерпевает никаких изменений на протяжении длительного времени. Даже наоборот - при том, что современное общество шагнуло далеко вперед в различных областях знаний, система управления государством упрощается. Отменяются различные цензы: снижается возраст избирателей (в большинстве стран), появляется законодательно необходимый гендерный паритет в списочном составе кандидатов в депутаты (Франция), устраняется ценз грамотности (США) и т. д. Отсутствуют законодательно закрепленные новые образовательные цензы при реализации пассивного избирательного права.

Развитие системы управления идет только по направлениям, не связанным или слабо связанным с избирательной системой: финансовые надгосударственные институты, транснациональные корпорации, манипуляции массовым сознанием, применение новых форм административного управления, которые обычно объединяют определением «новый публичный менеджмент», теория политических сетей, системы многоуровневого управления [11].

Таким образом, явно прослеживается отставание развития (отсутствие адаптации) избирательной системы в условиях прогрессирующего по другим направлениям общества, что приводит к потере устойчивости системы управления.

Возможные направления совершенствования современных избирательных систем:

1) введение новых образовательных и интеллектуальных цензов для кандидатов на выборные должности;

2) введение цензов активного избирательного права, которые будут отсеивать людей, абсолютно не осознающих ответственность своего выбора и не способных понять принципиальную разницу в позициях кандидатов;

3) повышение компетентности выбора за счет введения неравного активного избирательного права, учитывающего профессионализм, социальный статус, уровень образования;

4) увеличение количества обратных связей (выборов), разбивка общегосударственной системы управления на функциональные подсистемы (не влияющие или слабо влияющие на государственную безопасность).

5) применение косвенных выборов;

6) увеличение количества и повышение качества институтов общественного контроля над процедурой выборов;

7) отсеивание кандидатов на наиболее ответственные посты за счет урезания части гражданских прав их самих и членов их семьи, позволяющих реализовывать «коммерческие» интересы, с одновременным предоставлением «переходящей» материальной компенсации без права распоряжения; 
8) адаптация методик принятия групповых решений для применения в избирательной системе.

В избирательных системах некоторых стран были, а в некоторых и сейчас присутствуют «зачатки» развития. Например, в Австралии активным избирательным правом не обладают лица, «не способные понимать и осознавать природу и значение голосования» [4]. В Исландии пассивным избирательным правом могут воспользоваться граждане с «безупречной репутацией», но при этом ни Конституция, ни Закон не раскрывают понятия «безупречной репутации» [7]. В некоторых штатах США существовало правило, что избиратель при регистрации мог получить в руки Конституцию США и должен был прочесть несколько строк и объяснить, как он их понимает [3]. Другими словами, нужно было продемонстрировать определенный уровень политического образования и образования вообще. В Великобритании, Франции и Германии существуют детальные предписания для чиновников, вынужденных предоставлять подробнейшую отчетность о своей профессиональной деятельности [12]. В США действует система непрямых выборов президента. В Китае - многоступенчатая система непрямых и неравных (голос городского жителя имеет больший вес относительно сельского) выборов [13]. В Германии - система непрямых выборов канцлера. Но комплексной новой избирательной системы, позволяющей значительно снизить негативные качества демократической формы правления, не предложено, что значительно снижает темпы развития всего человечества.

Остановимся подробнее на некоторых пунктах.

Первый и четвертый пункты взаимосвязаны. Рассмотрим их совместно. В результате развития науки и техники для поддержания эффективности управления необходимо постоянно повышать минимальный уровень образования представителей власти, в первую очередь законодательной. Объясняется это тем, что невозможно принять правильное решение по вопросу, в котором человек не обладает минимально необходимым уровнем квалификации. Система советников и заместителей по различным вопросам является полумерой. Необходимо создать такую конфигурацию системы управления, чтобы человек находящийся на руководящей должности, мог эффективно справляться со своими обязанностями, будучи профессионалом в одной, двух областях.

Решением данной проблемы может стать создание функциональных подсистем, построенных на основе заново созданных профсоюзных организаций. Создание реально работающих профсоюзов является обязательным условием развития, т. к. профсоюз является местом концентрации обратной связи общества. При этом профсоюз не должен обладать внутренней иерархией, т. к. это приводит к искажению информации и к переориентации её потоков (профсоюз начинает использоваться как инструмент воздействия на состоящих в нем людей). На основе современных технологий возможно создание систем, позволяющих концентрировать требования, проводить совместные акции, совместно вырабатывать решения, активно влиять на выборы должностных лиц, в обязанности которых входит решение вопросов по профилю профсоюза.

Создав систему управления на основе функциональных подсистем, необходимо контролировать уровень подготовки должностных лиц независимыми экспертными службами, формируемыми на базе профсоюзных организаций.

Рассмотрим второй пункт. Часть населения не понимает важность выборов, часть не верит в значимость своего голоса, часть осознает, что не может сделать правильный выбор, часть голосует случайным образом либо по подсказке начальства. Таким образом, довольно большая доля избирателей хоть и обладают активным избирательным правом, но абсолютно не ценят его. 


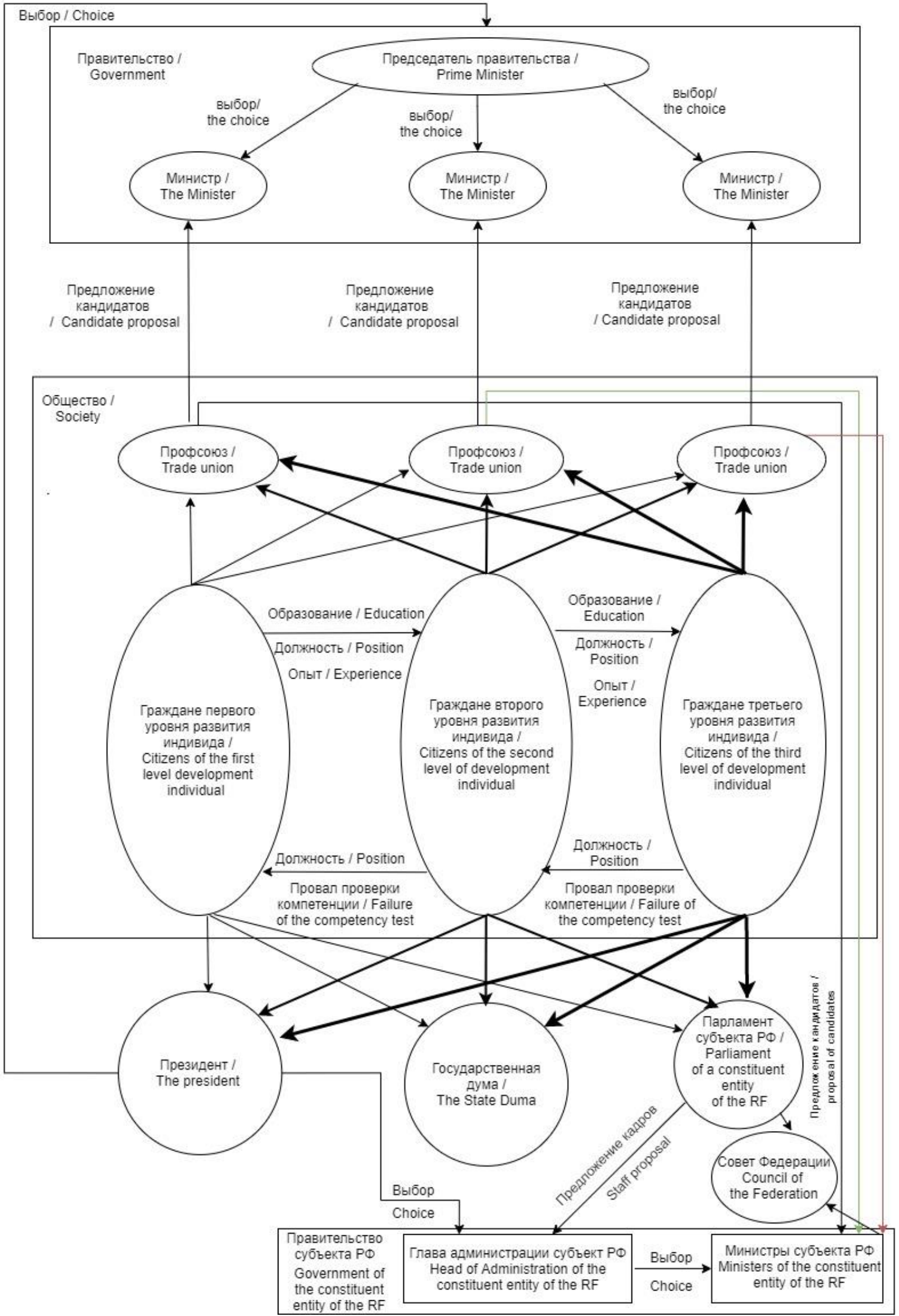

Рисунок. Упрощенная схема формирования власти на основе профсоюзов и неравного избирательного права

Figure. Simplified scheme of power formation based on trade unions and unequal suffrage 
Рассмотрим различные варианты решения. С учетом того, что стоимость организации выборов для бюджета страны зависит от количества голосующих, то возможно увеличить значимость голосов избирателей, осознающих ценность своего выбора, за счет предложения избирателям продажи своего права выбирать государству. Гражданин, для которого право выбора ничего не стоит, получит то, что ценит, - деньги. Государство оставит расходы на выборы на прежнем уровне. Медианный уровень интеллекта и образования избирателей повысится.

Вариант второй. Ввести единый государственный экзамен для получения активного избирательного права. Зашел в кабинку для голосования, ответил на часть вопросов теста, получил право проголосовать. Не ответил - готовься к следующим выборам, вне зависимости от образования и социального статуса.

Рассмотрим третий, пятый и восьмой пункты. Для принятия группового решения известны различные методики, часть из которых возможно использовать в избирательных системах. На данный момент используется метод основанный на предварительном обсуждении и равном голосовании. Но этот метод не единственный из возможных. Например, при выработке решения группой экспертов существует метод голосования на основе весовых коэффициентов. Для повышения эффективности избирательной системы возможно разделить избирателей на различные группы с различными коэффициентами значимости голоса. Деление на группы произвести, например, по уровню образования, успешности в профессиональной деятельности, опыту. На рисунке приведена схема, уточняющая способы повышения эффективности избирательной системы (толщина линии определяется весовым коэффициентом значимости голоса избирателя, который зависит от его принадлежности к разным группам по уровню развития).

В случае применения неравного голосования обостряется и без того значимый вопрос - контроль над процедурой выборов. В качестве примера шестого пункта можно привести уход от процедуры тайного голосования. Сначала на уровне выборов в государственную думу и выборов президента, потом на уровне региональных выборов. Проведение открытого голосования (неанонимные списки проголосовавших) минимизирует риски фальсификации результатов. Открытое голосование поспособствует развитию положительных качеств человека - смелости при принятии решения и ответственности за него, что является необходимым условием развития гражданского общества. Быть уволенным избиратель должен бояться гораздо меньше, чем выбрать президента (или депутата), не способного эффективно управлять страной.

О седьмом пункте списка задумывался еще Платон. Но поскольку власть имущие очень трепетно относятся к своему финансовому состоянию, как к гарантии фактического сохранения привилегий власти даже в результате юридической ее утери, то его идеи приводятся в жизнь очень медленными шажками, за каждый из которых идет битва не на жизнь, а на смерть на протяжении всей истории развития общества. На данный момент в ведущих демократических, социальных, правовых странах не позволяется использовать служебное положение для повышения своего благосостояния. Однако не решена проблема финансирования избирательных кампаний, хотя видимость борьбы с данной проблемой успешно создается уже длительное время. Не решена проблема лоббирования интересов «семей». В качестве следующего шага к устранению «коррупционно-клановой» проблемы необходимо отбирать все имущество и все наследственные права избранного, назначенного на важнейшие государственные должности (президент, члены парламента, председатель правительства, министры), в пользу государства с предоставлением всех необходимых условий для жизни и работы пожизненно. При этом уровень этих условий жизни должен зависеть от уровня развития государства. 
Bсе приведенные выше варианты совершенствования избирательной системы необходимы, чтобы не наступать повторно на грабли позднего СССР - бездарную власть. При достаточно высоком уровне образования в СССР в целом высший политико-управленческий слой отличался едва ли не самыми худшими культурнообразовательными характеристиками среди других категорий лиц умственного труда в стране [14].

\section{Выводы}

Вопрос эффективного управления государством многогранен и сложен. Развитие существующих избирательных систем является не единственной задачей из тех, решение которых необходимо для нового скачка развития общества, но она является ключевой для обеспечения последовательного и наименее болезненного перехода к эффективной и по возможности адаптируемой под новые вызовы системе управления государством.

\section{СПИСОК ЛИТЕРАТУРЫ}

1. Современные избирательные системы. Вып. 1. Великобритания, Канада, Мексика, Польша / Д.В. Лафитский, Н.М. Касаткина, А.Г. Орлов, Н.Ю. Трещетенкова. - М.: РЦОИТ: Норма, 2006. - 496 с.

2. Орлов А.Г., Лейбо Ю.И., Ракитская И.А. Современные избирательные системы. Вып. 2. Аргентина, Германия, Швеция. - М.: РЦОИТ: Норма, 2007. -320 с.

3. Современные избирательные системы. Вып. 3. Испания, США, Финляндия, Япония / А.Г. Орлов, В.И. Лафитский, И.А. Ракитская, Т.О. Кузнецова. - М.: РЦОИТ: Новости, 2009. - 448 с.

4. Современные избирательные системы Вып. 4. Австралия, Венесуэла, Дания, Сербия / Т.И. Чурсина, А.Г. Орлов, И.А. Ракитская, К.А. Половченко. - М.: РЦОИТ: Иноктаво, 2009. - 480 с.

5. Современные избирательные системы. Вып. 5. Индия, Венесуэла, Ирак, Уругвай, ЮАР / Н.Б. Шлыкова, М.А. Сапронова, А.Г. Орлов, Е.В. Черепанова. - М.: РЦОИТ: Иноктаво, 2010. - 496 с.

6. Современные избирательные системы. Вып. 6. Австрия, Ирландия, Норвегия, Чили / Е.А. Водяницкая, П.С. Гвоздев, И.А. Ракитская, А.Г. Орлов. - М.: РЦОИТ, 2011. - 512 с.

7. Современные избирательные системы. Вып. 7. Египет, Исландия, Колумбия, Пакистан / М.А. Сапронова, И.А. Ракитская, А.Г. Орлов, Н.Б. Крысенкова. - М.: РЦОИТ, 2012. - 464 с.

8. Современные избирательные системы. Вып. 8. Бразилия, Франция, Чехия, Южная Корея / А.Г. Орлов, М.А. Мещерякова, С.Я. Павлов, Т.О. Кузнецова. - М.: РЦОИТ, 2013. - 488 с.

9. Современные избирательные системы. Вып. 9. Индонезия, Словакия, Филиппины, Хорватия / Л.М. Ефимова, И.А. Ракитская, А.Г. Орлов, К.А. Половченко. - М.: РЦОИТ, 2014. - 512 с.

10. Володенков С.В. Современная политическая коммуникация как инструмент манипулирования общественным сознанием // Вестник Московского университета. Серия 12 «Политические науки». 2012. - № 5 - C. 89-103.

11. Чихарев И.А., Рамонова М.А. Понятие и основные концепции многоуровневого управления в мирополитическом дискурсе // Вестник Московского университета. Серия 12 «Политические науки». 2011. - № 5 - C. 3-16.

12. Будущее представительной демократии и парламентских учреждений в России и современном мире / С.В. Володенков, А.Л. Зверев, И.И. Кузнецов, Н.Р. Сетов, К.О. Телин // Вестник Московского университета. Серия 12 «Политические науки». - 2013. - № 1 - С. $27-87$.

13. Борзова Е.П., Чистяков А.Н., Бурдукова И.И. Политические и избирательные системы государств Азиатско-Тихоокеанского региона. Том 2. - СПб.: СПбКО, 2013. - 360 с.

14. Волков С.В. Интеллектуальный слой в советском обществе. URL: http://swolkov.org/ins/index.htm (дата обращения 12.12.2019).

Поступила 24.03.2020 2. 
UDC 342.84

\title{
STAGNATION OF ELECTORAL SYSTEMS
}

\author{
Alexander N. Chudinov, \\ chudinov_al@mail.ru \\ Omsk State Technical University, \\ 11, Mira avenue, Omsk, 644050, Russia
}

Alexander N. Chudinov, Cand. Sc., associate professor, Omsk State Technical University.

The paper substantiates the need to create an open electoral system as a regulatory mechanism for public administration and introduces the signs of ineffectiveness of universal equal votes of voters. The lack of development of electoral systems is shown; the arguments for the necessity of their development are presented. The author has proposed the directions of possible improvement of electoral systems.

Key words: Electoral system, effective government, unequal suffrage, electoral qualification.

\section{REFERENCES}

1. Lafitskiy D.V., Kasatkina N.M., Orlov A.G., Treshchetenkova N.Yu. Sovremennye izbiratelnye sistemy. Vyp. 1. Velikobritaniya, Kanada, Meksika, Polsha [Modern electoral systems. Iss. 1: Great Britain, Canada, Mexico, Poland]. Moscow, RTSOIT Publ., Norma Publ., 2006. 496 p.

2. Orlov A.G., Leybo Yu.I., Rakitskaya I.A. Sovremennye izbiratelnye sistemy. Vyp. 2. Argentina, Germaniya, Shvetsiya [Modern electoral systems. Iss. 2: Argentina, Germany, Sweden]. Moscow, RTSOIT Publ., Norma Publ., 2007. 320 p.

3. Orlov A.G., Lafitskiy V.I., Rakitskaya I.A., Kuznetsova T.O. Sovremennye izbiratelnye sistemy. Vyp. 3. Ispaniya, SShA, Finlyandiya, Yaponiya [Modern electoral systems. Iss. 3: Spain, USA, Finland, Japan]. Moscow, RTSOIT Publ., Novosti Publ., 2009. 448 p.

4. Chursina T.I., Orlov A.G., Rakitskaya I.A., Polovchenko K.A. Sovremennye izbiratelnye sistemy. Vyp. 4. Avstraliya, Venesuela, Daniya, Serbiya [Modern electoral systems. Iss. 4: Australia, Venezuela, Denmark, Serbia]. Moscow, RTSOIT Publ., Inoktavo Publ., 2009. 480 p.

5. Shlykova N.B., Sapronova M.A., Orlov A.G., Cherepanova E.V Sovremennye izbiratelnye sistemy. Vyp. 5. Indiya, Venesuela, Irak, Urugvay, YuAR [Modern electoral systems. Iss. 5: India, Venezuela, Iraq, Uruguay, South Africa]. Moscow, RTSOIT Publ., Inoktavo Publ., 2010. 496 p.

6. Vodyanitskaya E.A., Gvozdev P.S., Rakitskaya I.A., Orlov A.G. Sovremennye izbiratelnye sistemy. Vyp. 6. Avstriya, Irlandiya, Norvegiya, Chili [Modern electoral systems. Iss. 6: Austria, Ireland, Norway, Chile]. Moscow, RTSOIT Publ., 2011. 512 p.

7. Sapronova M.A., Rakitskaya I.A., Orlov A.G., Krysenkova N.B. Sovremennye izbiratelnye sistemy. Vyp. 7. Egipet, Islandiya, Kolumbiya, Pakistan [Modern electoral systems. Iss. 7: Egypt, Iceland, Colombia, Pakistan]. Moscow, RTSOIT Publ., 2012. 464 p.

8. Orlov A.G., Meshcheryakova M.A., Pavlov S.Ya., Kuznetsova T.O. Sovremennye izbiratelnye sistemy. Vyp. 8. Braziliya, Frantsiya, Chekhiya, Yuzhnaya Koreya [Modern electoral systems. Iss. 8: Brazil, France, Czech Republic, South Korea]. Moscow, RTSOIT Publ., 2013. 488 p.

9. Efimova L.M., Rakitskaya I.A., Orlov A.G., Polovchenko K.A. Sovremennye izbiratelnye sistemy. Vyp. 9. Indoneziya, Slovakiya, Filippiny, Khorvatiya [Modern electoral systems. Iss. 9: Indonesia, Slovakia, Philippines, Croatia]. Moscow, RTSOIT Publ., 2014. 512 p.

10. Volodenkov S.V. Sovremennaya politicheskaya kommunikatsiya kak instrument manipulirovaniya obshchestvennym soznaniyem [Modern political communication as a tool for manipulating public consciousness]. Vestnik Moskovskogo universiteta. Seriya 12 «Politicheskie nauki», 2012, no. 5, pp. 89-103. 
11. Chikharev I.A., Ramonova M.A. Ponyatie i osnovnye kontseptsii mnogourovnevogo upravleniya v miropoliticheskom diskurse [The concept and basic concepts of multilevel governance in the world political discourse]. Vestnik Moskovskogo universiteta. Seriya 12 «Politicheskie nauki», 2011, no. 5, pp. 3-16.

12. Volodenkov S.V., Zverev A.L., Kuznetsov I.I., Setov N.R., Telin K.O. Budushchee predstavitelnoy demokratii i parlamentskikh uchrezhdeniy v Rossii i sovremennom mire [The future of representative democracy and parliamentary institutions in Russia and the modern world]. Vestnik Moskovskogo universiteta. Seriya 12 «Politicheskie nauki», 2013, no. 1, pp. 27-87.

13. Borzova E.P., Chistyakov A.N., Burdukova I.I. Politicheskie i izbiratelnye sistemy gosudarstv AziatskoTikhookeanskogo regiona. T. 2 [Political and electoral systems of the states of the Asia-Pacific region. Vol. 2]. St. Petersburg, SPbKO Publ., 2013. 360 p.

14. Volkov S.V. Intellektualny sloy $v$ sovetskom obshchestve [The intellectual layer in the Soviet society]. Available at: http://swolkov.org/ins/index.htm (accessed 12 December 2019).

Received: 24 March 2020. 